\title{
Prosopografia dos diretores da Compagás
}

Guilherme Neotti ${ }^{1}$

Laércio Mikos²

- Enviado em 30/09/2017

- Aprovado em 08/12/2017

\section{Prosopografia}

A partir de 1970, com os trabalhos de Pierre Bourdieu, a técnica prosopográfica serviu para verificar a reprodução de grupos sociais nas esferas públicas francesas, e assim vem sendo inserida nos Estudos Sociais (MONTEIRO, 2014).

A prosopografia é um método que estuda o micro para entender se entender o macro. O método não se baseia nas grandes estruturas sociais (MONTEIRO, 2014), mas estuda os perfis individuais buscando entender a reprodução social em certo contexto histórico.

Com a biografia podemos acompanhar a carreira profissionalizante dos indivíduos estudados. Assim é possível ver as opções escolhidas que o posicionaram no mundo social e localizar trajetos comuns entre os estudados (MONTEIRO, 2014). Ao fim do processo é possível criar um perfil social gerado a partir das semelhanças encontradas nas biografias.

A prosopografia se torna uma abordagem inicial, ainda sem uma teoria substantiva, mas que nos permite compreender fenômenos e grupos políticos, sociais e culturais (MONTEIRO, 2014).

\section{Importância da instituição: Compagás}

A Compagás (Companhia Paranaense de Gás) é a concessionária responsável pela distribuição de gás natural canalizado no Estado do Paraná, cuja concessão foi outorgada em 06/07/1994 (COMPAGÁs) e

1

${ }^{2}$ laerciomikos@hotmail.com 
iniciou suas atividades em outubro de 1998, com a distribuição do gás de refinaria a indústrias de Curitiba, Araucária e Campo Largo (COMPAGÁS, 2014).

A companhia tem como acionistas a Companhia Paranaense de Energia - Copel, com 51\% das ações, a Petrobrás Gás S.A. - Gaspetro, com 24,5\% e a Mitsui Gás e Energia do Brasil Ltda., com 24,5\% (COMPAGÁS).

Em 1998, O governador Jaime Lerner inaugurou na Cidade Industrial de Curitiba, o primeiro ramal de distribuição da Companhia em uma das cinco primeiras indústrias beneficiadas, a Peróxidos do Brasil Ltda., fabricante de água oxigenada. Na época, com uma capacidade de fornecimento de 250 mil metros cúbicos de gás por dia, ligada também, à Philip Morris, Gerdau, Adesi Indústria e Comércio de Adesivos (primeiro cliente na cidade de Araucária, usa os serviços da companhia desde o início de sua operação (COMPAGÁs, 2016)) e a Novo Nordisk Bill Industria (Folha de Londrina, 1998).

Em 1999, iniciou-se a operação de transporte de gás natural do Gasoduto Bolívia-Brasil (GASBOL) (TBG,2017). Segundo FILHO (2002, p. 100):

Em julho de 1999, o Gasoduto Brasil-Bolívia (Gasbol) deu início a suas operações no Estado de São Paulo e, em março do ano seguinte, era inaugurado o trecho referente aos estados do Sul. Depois de mais de dois anos de obras, completava-se a etapa final de um dos principais projetos de investimento em infra-estrutura implementado pelo governo brasileiro na década passada.

Em 2000, a empresa passou a ser a primeira distribuidora do Sul do país a fornecer o gás natural aos seus clientes (COMPAGÁS, 2014). Com a chegada do produto ao Paraná, foi construído, na região Industrial de Araucária, o City Gate da empresa: estação de recebimento do gás natural vindo do gasoduto Bolívia-Brasil (COMPAGÁs,2016).

No ano seguinte foi realizada a primeira ligação a um cliente comercial, o Hotel Dom Ricardo, em São José dos Pinhais (INSTITUTO, 2011). O Paraná foi o primeiro estado da região sul que começou a utilizar o gás natural para o segmento veicular, tendo como o posto Chu no bairro Rebouças na capital paranaense como o primeiro posto abastecido pela Compagás e até o final daquele ano, já totalizavam 6 postos oferecendo o gás aos seus clientes (BEM PARANÁ, 2011).

Em 2002, iniciou o fornecimento de gás natural à Usina Elétrica a Gás de Araucária - UEG Araucária (COMPAGÁS, 2016) e ao Edifício Millenium, situado no bairro do Ecoville em Curitiba. Foi o primeiro contrato para fornecimento de gás natural residencial para um edifício da cidade (GASNET, 2002).

A empresa iniciou o fornecimento de gás natural veicular ao primeiro posto de combustível fora de Curitiba em 2006, em São José dos Pinhais, o posto Tio Zico, de bandeira Ipiranga (GASNET, 2006). 
No ano seguinte, a Companhia registrou o recorde de venda de 1 milhão de $\mathrm{m}^{3} \mathrm{em}$ um dia e

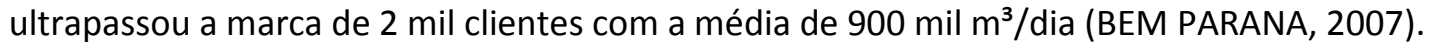

Em 2010, o volume de venda de gás natural era de $960 \mathrm{mil} \mathrm{m³} /$ dia em média e o número de consumidores de gás natural de 9.289. O segmento residencial é o que mais cresceu em número de clientes, alcançando o índice de 39,6\% em relação ao ano anterior. Esses dados foram comemorados pelo diretor-presidente da época Stênio Jacob, segundo ele: "Este crescimento comprova a ótima reação e aprovação do mercado pelo gás natural como um combustível eficaz, seguro e econômico" (JHONATAN, 2011).

Em 2012, a Compagás iniciou o fornecimento de gás natural aos clientes residenciais de Ponta Grossa, nos Campos Gerais. O primeiro a receber foi o edifício Monet, localizado no bairro Estrela. A ampliação da rede de distribuição de gás natural coincidiu com os 10 anos de fornecimento ao segmento residencial (CIDADAO, 2012).

Em 2014, a companhia foi a empresa brasileira que mais cresceu, passando da posição 960a para $342^{a}$ no ranking das maiores do país. As vendas foram as maiores já registradas pela companhia chegando a média de $2.803 .114 \mathrm{~m}^{3} /$ dia. Volume de gás esse que representa alta de $169 \%$ em relação ao comercializado em 2013 (1.042.123 $\left.\mathrm{m}^{3} / \mathrm{dia}\right)$.

O segmento residencial fechou 2014 com 25.466 unidades domiciliares com o gás natural. O aumento de mais de 5 mil clientes elevou o consumo de gás e a média diária de consumo passou de 14.058 $\mathrm{m}^{3}$, em 2013, para $15.241 \mathrm{~m}^{3}$ em 2014 (COMPAGÁS, 2015).

O faturamento foi de R\$ 2,034 bilhões, muito superior ao R\$ 483 milhões em 2013 e o lucro líquido, por sua vez, subiu de R\$ 18 milhões para R\$ 60 milhões. Esses dados são justificados pelo fato de que até 2013, a Compagás fazia apenas o transporte do gás natural até a Usina Elétrica a Gás de Araucária e a partir de 2014 a companhia passou também a vender o combustível (JASPER,2015).

Em 2016, o volume de vendas da Compagás atingiu a média anual de $1.301 .323 \mathrm{~m}^{3} /$ dia, queda de 52\% em relação a 2015. O mercado industrial em desaceleração devido à crise econômica e política foi o principal motivo para o menor volume de gás comercializado. Contudo, os segmentos residencial, comercial e matéria-prima foram os únicos setores que se mantiveram com crescimento durante o ano (VALOR,2017).

Em 2017, o governo do Paraná Beto Richa (PSDB) fechou uma parceria com a petrolífera Shell que prevê a criação de um plano de expansão do gás natural no estado ao longo do ano de 2018. A ideia da Copel que lançou uma chamada pública em 2015 é construir 300 quilômetros de novos gasodutos e três novas termelétricas - em Araucária (Região Metropolitana de Curitiba), no litoral e na região Sul do estado. Um dos objetivos é oferecer gás natural a um preço melhor ao consumidor paranaense (GARCIA, 2017). 
Na mesma data em que o governador assinou o plano de expansão, 17 de outubro de 2017, saiu em reportagem no jornal Gazeta do Povo, que o chefe da Casa Civil do Paraná, Valdir Rossoni, e o presidente do Banco Nacional de Desenvolvimento Econômico e Social (BNDES), Paulo Rabello de Castro, assinaram em 12 de junho um termo de cooperação que firmou acordo para privatizar empresas públicas e entre as empresas paranaenses, consta a Compagás. (JUNIOR, 2017). Segundo reportagem do jornal (JUNIOR, 2017):

A "desestatização" pretendida pelo BNDES não se trata só de vender empresas públicas. No acordo de cooperação assinado pelo Paraná, pelo menos sete formas de se fazer negócio são sugeridas pelo banco: alienação (venda) de participação societária do poder público, aumento ou abertura de capital social de empresas estatais, concessões, permissões, parcerias público-privadas (PPPs) e arrendamento de bens. Nessa operação, o BNDES é uma extensão do governo federal.

Até a conclusão deste artigo não foi encontrado nenhuma nova informação referente à expansão e tão pouco, a privatização da Companhia paranaense de gás.

\section{Diretor- Presidente}

O foco da pesquisa foi encontrar dados dos diretores-presidente na Compagás no período de 2003 até 2017 (atual) a fim de se construir uma prosopografia.

A seguir será feito uma pequena descrição sobre cada presidente que assumiu a comando da empresa no período descrito anteriormente.

\section{Jonel Nazareno lurk}

Assumiu em junho de 2017 (ADMISSÕES E DESLIGAMENTOS EM 2017; 2017) sendo o presidente em exercício atualmente. É graduado em duas faculdades: Engenharia Civil e licenciatura em matemática pela Universidade Estadual de Ponta Grossa (ESCAVADOR, 2017).

Tem experiência na área de meio ambiente e energia. Fez mestrado em Ciência do Solo em 2003 e uma especialização em gestão e engenharia ambiental em 2000 ambos na universidade Federal do Paraná (ESCAVADOR, 2017), além de cursos e participação em eventos na área ambiental.

Trabalhou em diversos cargos públicos antes de assumir o cargo atual. Foi engenheiro da Companhia de saneamento do Paraná (Sanepar) na década de 90, além de ser superintendente do IBAMA no mesmo período (ESCAVADOR, 2017). 
Mas recentemente, em 2011 foi secretário de estado na Secretária do Meio Ambiente e recursos hídricos e em 2013 assumiu a diretoria da companhia paranaense de energia elétrica (Copel), onde ficou até 2017 antes de assumir a Compagás (ESCAVADOR, 2017).

Enquanto foi secretário do meio ambiente foi investigado pelo Ministério Público por conceder licenças ambientais para parentes. Filhos do Diretor conseguiram licença para a instalação de CGH - Central Geradora de Hidrelétrica (GAZETA DO POVO, 2013).

Em 2014, o Ministério Público arquivou o processo. Na ocasião do arquivamento, Jonel lurk se posicionou a respeito dizendo que qualquer cidadão pode requerer essas centrais geradoras, e que o processo foi dentro dos trametes legais, sem privilégios (GAZETA DO POVO, 2013).

\section{Fernando Eugenio Ghignone}

Assumiu em janeiro de 2015 (ANPR, 2015) e se desligou do cargo em junho de 2017 (ADMISSÕES E DESLIGAMENTOS EM 2017; 2017), passando a presidência para o Jonel Nazareno lurk. Após deixar a Compagás já ganhou outra colocação publica, sendo agora o novo secretário de Administração e Previdência (RPC CURITIBA, 2017).

Formando em Administração, assumiu diversos cargos públicos estatuais e municipais em Curitiba, e antes de assumir a Compagás era presidente da Sanepar desde 2011 (ANPR, 2015).

Era filho de José Eugenio Ghignone, o seu "Dude" como era conhecido, livreiro da tradicional livraria Ghignone que herdou do seu pai (FELIX, 2016). Inaugurada em 1921, chegou a ter 13 lojas na capital paranaense, mantendo no fim da livraria uma loja que funciona na Rua Comendador Araujo, no centro de Curitiba que fechou por falta de segurança (FELIX, 2016).

Sua carreira publica iniciou na década de 80, assumindo o cargo de secretario Cultura, Esporte e Turismo do estado do Paraná. Posteriormente foi presidente dos conselhos de Cultura, Esporte, Turismo além de presidir a fundação Guaíra e a Celepar (SANEPAR, 2011).

Foi presidente da Embrafilmes S.A. viabilizando muitos filmes e documentários, além de ser parte do conselho da Funarte e conselho federal de Censura (SANEPAR, 2011).

Nos anos 2000, foi secretário de comunicação social da prefeitura de Curitiba. Além dos cargos públicos empreendeu em várias áreas, como por exemplo, turística, imobiliária e logística. E assim chegou à presidência do Clube dos Diretores Lojistas de Curitiba e tornou-se membro do Conselho Político da Associação Comercial Do Paraná - ACP (SANEPAR, 2011).

Na direção da Sanepar levou algumas multas do Tribunal de Contas por contração de serviços de forma irregular. 
Em 2015, o Tribunal de Contas (TC-PR) aplicou seis multas a ex-gestores entre eles, Fernando Ghignone (TCE-PR, 2015). Para o tribunal ouve irregularidade na contratação de um serviço de envase de água potável (embalagem da água em copos e distribuição em eventos). A defesa alega que foram feitas pesquisa de mercado e o presidente da Assesa se absteve de votar sobre o assunto na reunião do conselho. Além disso, a defesa alega que a falta de nota fiscal se deve ao fato do serviço não ser enquadrado na categoria que obriga a nota pela prestação do serviço (TCE-PR, 2015).

Porém essa não é a única fez que Fernando levou multa por irregularidades a frente da Sanepar. Por realizar despesas sem licitação acima dos limites legais, sendo o limite de 16 mil e o gasto feito pelo gestor de 199 mil reais, Ghignone recebeu novamente três multas do tribunal (REDAÇÃO, 2017).

O Tribunal de contas determinou ainda que a Sanepar planeje seus gastos de forma corporativa eliminando contratações diretas e respeitando o limite legal. Em defesa, foram justificados os gastos como de urgência e Ghignone entrou com recurso que será julgado ainda (REDAÇÃO, 2017).

\section{Luciano Pizzatto}

Assumiu o cargo em janeiro de 2011 (LINKED ID, 2017) e deixou o cargo da presidência no fim de 2014 para a posse do Fernando Eugenio Ghignone em janeiro de 2015 (ANPR, 2015). No portal da transparência da empresa apenas aparece o quadro de funcionários de setembro de 2012 até os dias atuais (RELAÇÃO PESSOAL EM 2012, 2017), assim foi pesquisadas fontes externa para obter os nomes e as datas de presidentes anteriores a 2012.

Luciano estudou no curso técnico em eletrônica na Escola Técnica Federal do Paraná e após se formar cursou em 1976, Engenharia Florestal na Universidade Federal do Paraná (FGV CPDOC, 2017).

Após se formar assumiu diversos cargos importantes em órgãos florestais como: Membro da diretoria do Sindicato de Comercio Atacadista de Madeiras do Paraná; Presidente da Associação Paranaense de Engenheiros Florestais; Assumiu em 1985 a vice-presidência da Sociedade Brasileira de Engenheiros Florestais; Em 1988, dirigiu o departamento de parques nacionais e reservas equivalentes do Instituto Brasileiro de Desenvolvimento Florestal (IBDF), que posteriormente se tornaria o atual IBAMA (FGV CPDOC, 2017).

A partir de 1986 tentou ingressar na vida pública como deputado estadual pelo PMDB conseguindo uma suplência. Em 1889 se elegeu deputado estadual participando de várias comissões envolvendo assuntos ambientais (FGV CPDOC, 2017). Em 1990, se elegeu deputado federal pelo PRN e em 1998 se reelegeu deputado federal pelo PFL. Mais recentemente tentou candidatura ao senador não sendo eleito (FGV CPDOC, 2017). 
Casou-se com Dora Maria Ficinski Dunin Pizzatto com quem teve três filhos (FGV CPDOC, 2017). Dora Maria Ficinski é diretora presidente do ICS - Instituto Curitiba de Saúde (ICS, 2017). A família Ficinski Dunin apresenta histórico na administração pública (FGV CPDOC, 2017).

Lubomir Ficinski Dunin se formou na primeira turma de arquitetura da UFPR em 1964 e já na década de 60 começou a trabalhar na administração municipal ajudando a criação do próprio IPPUC. Foi um dos membros da equipe idealizadora do sistema de transportes com canaletas que foi reproduzida mais tarde no mundo todo. Além de projetar alguns terminais de ônibus de Curitiba. Criou o parque Barigui e a torre da Telepar, hoje propriedade da empresa Oi. Em 2011 foi diretor de transportes da URBS. Antes de morrer trabalhava em um projeto especial para o presidente Rafael Grega no IPPUC (PAGOTO, 2017).

Foi citado num processo por mau uso do dinheiro público enquanto foi presidente da Compagás.

O tribunal de contas investigou e absorveu (com o voto do presidente Durval Amaral) Luciano Pizzatto do pagamento de multa e restituição de dinheiro aos cofres públicos pelo prejuízo causado em sua gestão na direção da Compagás (FELIX, 2017). O prejuízo foi causado pelo aluguel de um imóvel, no bairro do Batel, que foi alugado tendo despesas como IPTU e energia elétrica sendo pagas mensalmente pela companhia, porém o imóvel ficou abandonado sem ser usado pela empresa (FELIX, 2017).

Atualmente é secretário do Governo do estado do Paraná (LINKED ID, 2017).

\section{Stênio Sales Jacob}

Assumiu o cargo em agosto de 2010 (COMPAGÁs, 2010) e deixou o cargo em dezembro do mesmo ano para que Luciano Pizzatto assumisse em janeiro do ano seguinte.

Stênio Sales tem uma grande experiência na parte administrativa pública. Antes de assumir a Compagás estava na presidência da Sanepar por sete anos (COMPAGÁS, 2010) e foi presidente da Associação das Empresas de Saneamento Básico Estaduais - AESBE (CESAN, 2008).

Anteriormente foi presidente da Urbanização de Curitiba (URBS) e Secretário Municipal dos Transportes em Curitiba na década de 80. Na década de 90 assumiu a Sanepar (1991-1994) além de assumir cargos públicos na cidade De Blumenau: Presidente da Fundação Hospitalar de Blumenau e Secretário de Obras do município (CESAN, 2008).

Já teve seus bens indisponíveis em uma ação de improbidade administrativa em Blumenau (SC), quando foi secretário de obras do município, suspeito de desviar mais de 2 milhões de reais dos cofres públicos (OLIVEIRA, 2007).

\section{Luiz Carlos Meinert}


Assumiu o cargo de presidência em agosto de 2005 (COMPAGÁs, 2005) e deixou o cargo em agosto de 2010 (CM, 2010) para o Stênio Sales Jacob assumir.

É formado em Direito e Economia, assumindo a presidência com 63 anos (COMPAGÁS, 2005).

Trabalhou em diversas funções na administração pública, como por exemplo, secretário municipal de Administração e Recursos Humanos e secretário da Fazenda de Joinville (SC). Como empresário fundou a empresa Biofi de produtos tecnológicos e trabalhou na Bioext relacionada a produtos de biotecnologia (COMPAGÁS, 2005).

Foi diretor da Escola de Teatro Bolshoi no Brasil, sendo investigado por desvio de dinheiro em sua gestão. O Tribunal Regional Federal da 40 Região julgou improcedente e inocentou todos os acusados, entre eles os diretores, da ação que denunciava desvio de verbas repassadas pelos Correios para a Escola de teatro Bolshoi por meio da lei Rouanet nos anos de 2002 a 2004 (SINTESE, 2017).

\section{Rubico Camargo}

O Publicitário foi presidente da Compagás de fevereiro de 2003 até agosto de 2005 (COMPAGÁS, 2005) passando seu lugar o Luiz Carlos Meinert.

Tem experiência na gestão pública. Foi diretor da secretaria de Comunicação Social do Paraná antes de assumir a Compagás. Posteriormente a seu mandado na empresa, trabalhou em outras áreas públicas como na diretoria de Planejamento e Desenvolvimento da URBS e no Instituto de Pesos e Medidas do Paraná.

Mais recentemente foi desnomeado do cargo que assumiu na Binacional Itaipu. Por indicação do deputado Rubens Bueno (PPS) assumiu a Itaipu porem o presidente, Michel Temer, iria exonerar do cargo o ex-diretor por ser ligado a um partido político (TUPAN, 2017).

\section{0 perfil dos diretores}

Podemos ter um perfil de todos que passaram na Compagás exercendo a função de diretorpresidente verificando que, em especial, todos os diretores presidentes já trabalharam em secretarias ou órgãos públicos antes de assumir a direção da Compagás seja no estado do Paraná como também em outro estado.

Tabela 1- Biografia dos presidentes da Compagás

\begin{tabular}{|c|c|c|c|}
\hline \multicolumn{3}{|c|}{ Jonel Nazareno lurk } \\
\hline Cargo Compagás & Graduação & Outros cursos & Experiência profissional \\
\hline Junho/2017 & Engenharia Civil & Mestrado em Ciência do Solo & Engenheiro (Sanepar); \\
\hline
\end{tabular}




\begin{tabular}{|c|c|c|c|}
\hline $\begin{array}{c}- \\
\text { Atual }\end{array}$ & $\begin{array}{c}\text { (UEPG); } \\
\text { Matemática (UEPG); }\end{array}$ & $\begin{array}{c}\text { (UFPR); } \\
\text { Participação em eventos e } \\
\text { cursos; }\end{array}$ & $\begin{array}{l}\text { Superintendente } \\
\qquad \text { (IBAMA); } \\
\text { Diretoria (Copel); }\end{array}$ \\
\hline $\begin{array}{l}\text { Secretarias Públicas } \\
\text { (municipais e } \\
\text { estaduais) }\end{array}$ & Laços políticos & Laços familiares & Processos \\
\hline $\begin{array}{l}\text { Meio Ambiente e } \\
\text { recursos hídricos }\end{array}$ & $\begin{array}{l}\text { Filiado ao PSB na } \\
\text { cidade de } \\
\text { Prudentopolis } \\
\text { (FILIWEB, 2017); }\end{array}$ & $\begin{array}{l}\text { Casado com Maria Lorena } \\
\qquad \text { Witcmichen lurk } \\
\text { (CINEMASPOKE, 2014); }\end{array}$ & $\begin{array}{l}\text { Investigado pelo } \\
\text { Ministério Público por } \\
\text { conceder licenças } \\
\text { ambientais para } \\
\text { parentes; }\end{array}$ \\
\hline \multicolumn{4}{|c|}{ Fernando Eugenio Ghignone } \\
\hline Cargo Compagás & Graduação & Outros cursos & Experiência profissional \\
\hline $\begin{array}{c}\text { Janeiro/2015 } \\
- \\
\text { junho /2017 }\end{array}$ & Administração & $\begin{array}{l}\text { Técnico em eletrônica (Escola } \\
\text { Técnica Federal do Paraná) }\end{array}$ & $\begin{array}{c}\text { Presidente (conselhos de } \\
\text { Cultura, Esporte, } \\
\text { Turismo); } \\
\text { Presidente (Guaíra; } \\
\text { Celepar); } \\
\text { Presidente (Embrafilmes } \\
\text { S.A); } \\
\text { Presidente (Clube dos } \\
\text { Diretores Lojistas de } \\
\text { Curitiba); } \\
\text { Membro (Conselho } \\
\text { Político da Associação } \\
\text { Comercial Do Paraná); }\end{array}$ \\
\hline $\begin{array}{l}\text { Secretarias Públicas } \\
\text { (municipais e } \\
\text { estaduais) }\end{array}$ & Laços políticos & Laços familiares & Processos \\
\hline $\begin{array}{c}\text { Cultura, Esporte e } \\
\text { Turismo; } \\
\text { Comunicação social; } \\
\text { Administração e } \\
\text { Previdência } \\
\text { (atualmente); }\end{array}$ & $\begin{array}{c}\text { Secretário } \\
\text { atualmente do } \\
\text { governo Beto Richa }\end{array}$ & $\begin{array}{l}\text { filho de José Eugenio } \\
\text { Ghignone, o seu “Dude" } \\
\text { (livraria Ghignone) }\end{array}$ & $\begin{array}{l}\text { Multas do Tribunal de } \\
\text { Contas por contração de } \\
\text { serviços de forma } \\
\text { irregular (Sanepar) }\end{array}$ \\
\hline \multicolumn{4}{|c|}{ Luciano Pizzatto } \\
\hline Cargo Compagás & Graduação & Outros cursos & Experiência profissional \\
\hline Janeiro/2011 & Engenharia Florestal & - & Diretoria (Sindicato de \\
\hline
\end{tabular}




\begin{tabular}{|c|c|c|c|}
\hline $\begin{array}{c}- \\
\text { Janeiro/2015 }\end{array}$ & (UFPR) & & $\begin{array}{c}\text { Comercio Atacadista de } \\
\text { Madeiras do Paraná); } \\
\text { Presidente (Associação } \\
\text { Paranaense de } \\
\text { Engenheiros Florestais); } \\
\text { vice-presidência } \\
\text { (Sociedade Brasileira de } \\
\text { Engenheiros Florestais); } \\
\text { presidente(Instituto } \\
\text { Brasileiro de } \\
\text { Desenvolvimento } \\
\text { Florestal); }\end{array}$ \\
\hline $\begin{array}{l}\text { Secretarias Públicas } \\
\text { (municipais e } \\
\text { estaduais) }\end{array}$ & Laços políticos & Laços familiares & Processos \\
\hline $\begin{array}{l}\text { Atualmente é } \\
\text { secretario do } \\
\text { Governo do estado } \\
\text { do Paraná; }\end{array}$ & $\begin{array}{l}\text { deputado estadual; } \\
\text { deputado federal; }\end{array}$ & $\begin{array}{l}\text { Casado com Dora Maria } \\
\text { Ficinski Dunin Pizzatto } \\
\text { (família Ficinski Dunin } \\
\text { apresenta histórico na } \\
\text { administração pública); }\end{array}$ & $\begin{array}{l}\text { Processo por mau uso do } \\
\text { dinheiro público } \\
\text { enquanto foi presidente } \\
\text { da Compagás; }\end{array}$ \\
\hline \multicolumn{4}{|c|}{ Stênio Sales Jacob } \\
\hline Cargo Compagás & Graduação & Outros cursos & Experiência profissional \\
\hline $\begin{array}{c}\text { Agosto/ } 2010 \\
- \\
\text { Dezembro /2010 }\end{array}$ & $\begin{array}{l}\text { Direito; } \\
\text { Economia; }\end{array}$ & - & $\begin{array}{c}\text { Presidente (Sanepar); } \\
\text { Presidente (Associação } \\
\text { das Empresas de } \\
\text { Saneamento Básico } \\
\text { Estaduais); } \\
\text { Presidente (Urbanização } \\
\text { de Curitiba (URBS)); } \\
\text { Presidente (Fundação } \\
\text { Hospitalar de Blumenau); }\end{array}$ \\
\hline $\begin{array}{l}\text { Secretarias Públicas } \\
\text { (municipais e } \\
\text { estaduais) }\end{array}$ & Laços políticos & Laços familiares & Processos \\
\hline Transportes & - & - & $\begin{array}{l}\text { (Já teve bens } \\
\text { indisponíveis em uma }\end{array}$ \\
\hline
\end{tabular}




\begin{tabular}{|c|c|c|c|}
\hline $\begin{array}{l}\text { (Curitiba); } \\
\text { Obras (Blumenau } \\
\text { (SC)); }\end{array}$ & & & $\begin{array}{c}\text { ação de improbidade } \\
\text { administrativa quando foi } \\
\text { secretário de obras em } \\
\text { Blumenau (SC)); }\end{array}$ \\
\hline \multicolumn{4}{|c|}{ Luiz Carlos Meinert } \\
\hline Cargo Compagás & Graduação & Outros cursos & Experiência profissional \\
\hline $\begin{array}{c}\text { agosto/2005 } \\
- \\
\text { agosto/2010 }\end{array}$ & - & - & $\begin{array}{c}\text { Fundador (empresa } \\
\text { Biofi); } \\
\text { Trabalhou (empresa } \\
\text { Bioext - ramo de } \\
\text { biotecnologia); } \\
\text { Diretor (Escola de Teatro } \\
\text { Bolshoi no Brasil); }\end{array}$ \\
\hline $\begin{array}{c}\text { Secretarias Públicas } \\
\text { (municipais e } \\
\text { estaduais) }\end{array}$ & Laços políticos & Laços familiares & Processos \\
\hline $\begin{array}{l}\text { Administração e } \\
\text { Recursos Humanos } \\
\text { (Joinville (SC)); } \\
\text { Fazenda (Joinville } \\
\text { (SC)); }\end{array}$ & - & - & $\begin{array}{c}\text { Investigado por desvio de } \\
\text { dinheiro em sua gestão } \\
\text { (Escola de Teatro Bolshoi } \\
\text { no Brasil); }\end{array}$ \\
\hline \multicolumn{4}{|c|}{ Rubico Camargo } \\
\hline Cargo Compagás & Graduação & Outros cursos & Experiência profissional \\
\hline $\begin{array}{c}\text { fevereiro / } 2003 \\
- \\
\text { agosto/2005 }\end{array}$ & Publicidade & - & $\begin{array}{c}\text { Diretoria (Planejamento e } \\
\text { Desenvolvimento da } \\
\text { URBS); } \\
\text { Trabalhou (Instituto de } \\
\text { Pesos e Medidas do } \\
\text { Paraná); }\end{array}$ \\
\hline $\begin{array}{c}\text { Secretarias Públicas } \\
\text { (municipais e } \\
\text { estaduais) }\end{array}$ & Laços políticos & Laços familiares & Processos \\
\hline Comunicação Social; & $\begin{array}{l}\text { indicação do } \\
\text { deputado Rubens } \\
\text { Bueno (PPS) para } \\
\text { assumir a Itaipu; }\end{array}$ & - & - \\
\hline
\end{tabular}

Fonte: Tabela desenvolvida pelos autores utilizando os dados da pesquisa de cada diretor,2017. 


\section{Considerações Finais}

Ao longo do tempo e de diversas gerações é acumulado capital social e político, e, além disso, conexões, o que cria uma 'ampla rede social' (OLIVEIRA, 2012) de interesses políticos e econômicos. É possível através dos perfis listados ver conexões que permitem a continuação do indivíduo no poder público.

Um dos melhores conceitos na contemporaneidade é o conceito da conciliação aliado ao conceito de adaptabilidade (OLIVEIRA, 2012). Há uma conciliação entre os indivíduos que faz com que eles passem por governos distintos ao longo do tempo e se adaptem sempre permanecendo na esfera pública.

Todos os diretores presidentes já trabalharam em secretarias ou órgãos públicos antes de assumir a direção da Compagás. Dois ex-diretores trabalham atualmente em secretarias no governo atual. Além disso, a trajetória na vida pública dos estudados é longa passando na gestão de governos distintos, em municípios distintos e distintos cargos. Em diversas secretarias, do meio ambiente, esporte e cultura, em obras, administrando escolas, empresas particulares, empresas públicas: Sanepar e Copel e diversos outros cargos.

A conexão de famílias da classe dominante com atividades públicas faz com que ações sociais se fundamentem em torno do Estado, com operações políticas- financeiras de mutuo benefício chegando até os acordos na informalidade (OLIVEIRA, 2012). Quase todos os estudados já responderam ou respondem processos por má administração quando foram secretários ou diretores em seu passado.

\section{Referências}

ADMISSÕES E DESLIGAMENTOS EM 2017. Compagás. Portal Da Transparência. Jun. 2017. Disponível em <http://www.Compagás.com.br/images/pdf/transparencia/2017/201706_mov_pessoal1.pdf> Acesso em: $12 / 10 / 17$.

ALVES, Arnaldo. Richa assina contrato para Compagás fornecer gás. 2015. Disponível em https://www.tribunadointerior.com.br/noticia/richa-assina-contrato-para-Compagás-fornecer-gas> Acesso em 05/11/2017.

ANPR. Fernando Eugênio Ghignone assume a Compagás. Bem Paraná. jan. 2015. Disponível em http://www.bemparana.com.br/noticia/366526/fernando-eugenio-ghignone-assume-a-Compagás> Acesso em: $12 / 10 / 17$.

BEM PARANA, 2007. Compagás bate recorde de vendas. Disponível em http://www.bemparana.com.br/noticia/30252/Compagás-bate-recorde-de-vendas > Acesso em 05/11/2017. 
BEM PARANÁ, 2011. Consumo de Gás Natural cresceu 330\% em 10 anos. Disponível em http://www.bemparana.com.br/noticia/177023/consumo-de-gas-natural-cresceu-330-em-10-anos>. Acesso em 05/11/2017.

CESAN. Stênio Jacob, da Sanepar, é o novo presidente da Aesbe. Noticias. mar. 2008. Disponível em < https://www.cesan.com.br/noticias/stenio-jacob-da-sanepar-e-o-novo-presidente-da-aesbe/> Acesso em: 15/10/17.

CIDADAO, 2012. Gás natural chega às residências de Ponta Grossa. Disponível em http://www.cidadao.pr.gov.br/modules/noticias/article.php?storyid=71145\&tit=Gas-natural-chega-asresidencias-de-Ponta-Grossa> Acesso em 05/11/2017.

CINEMASPOKE. Casamento Karina e André. abr. 2014. Disponível em < http://www.cinemaskope.com/casamento-karina-e-andre/> Acesso em: 26/11/17.

COMPAGÁS. A COMPAGÁS. Disponível em < http://www.Compagás.com.br/index.php/a-Compagásacesso-info> Acesso em: 04/11/2017.

COMPAGÁS tem novo diretor-presidente. Agência de notícias estado do Paraná. Energia. ago. 2010. Disponível em <http://www.historico.aen.pr.gov.br/modules/noticias/article.php?storyid=58704> Acesso em: 12/10/17.

COMPAGÁS tem novo presidente. Agência de notícias estado do Paraná. Copel. ago. 2005. Disponível em < http://www.historico.aen.pr.gov.br/modules/noticias/article.php?storyid=13777> Acesso em: 12/10/17.

COMPAGÁS já atente 300 clientes da área comercial com gás natural. Agência estadual de notícias, 2011. Disponível em http://www.aen.pr.gov.br/modules/noticias/article.php?storyid=62279\#> Acesso em 05/11/2017.

COMPAGÁS inicia obras de expansão da rede de gás natural em Araucária. Agência estadual de notícias, 2016. Disponível em: <http://www.aen.pr.gov.br/modules/noticias/article.php?storyid=90124> Acesso em 05/11/2017.

COMPAGÁS, 2014. Compagás comemora 20 anos com expectativa de faturamento de $\mathbf{2 , 4}$ bilhões em 2014. Disponível em < http://www.Compagás.com.br/index.php/noticias-rodape/289-Compagáscomemora-20-anos-com-expectativa-de-faturamento-de-2-4-bilhoes-em-2014> Acesso em: 04/11/2017.

COMPAGÁS, 2014. Compagás inicia obras para ampliação da rede nos campos gerais. Disponível em < http://www.Compagás.com.br/index.php/noticias-rodape/286-Compagás-inicia-obras-para-ampliacao-darede-nos-campos-gerais> Acesso em 05/11/2017.

COMPAGÁs, 2015. Compagás é a empresa brasileira que mais cresceu em 2014. Disponível em http://www.Compagás.com.br/index.php/noticias-rodape/367-Compagás-e-a-empresa-brasileira-quemais-cresceu-em-2014>. Acesso em 05/11/2017.

COMPAGÁS, 2016. Compagás inicia obras de expansão da rede de gás natural em araucária. Disponível EM < http://www.Compagás.com.br/index.php/noticias-rodape/479-Compagás-inicia-obras-de-expansaoda-rede-de-gas-natural-em-araucaria> Acesso em 05/11/2017

ESCAVADOR. Jonel Nazareno lurk. Pessoa física. set. 2017. Disponível em https://www.escavador.com/sobre/898501/jonel-nazareno-iurk\#profissional> Acesso em: 12/10/17.

FELIX Rosana. Morre o livreiro José Ghignone. Gazeta do Povo. Vida e Cidadania. jan. 2016. Disponível em http://www.gazetadopovo.com.br/vida-e-cidadania/morre-o-livreiro-jose-ghignonedpklrpqm1h47ezbmf49e7f4s0> Acesso em: 25/10/17. 
FELIX Rosana. TCE-PR livra Secretario de Richa de multa por aluguel de imóvel abandonado. Gazeta do Povo. Paraná. jun. 2017. Disponível em http://www.gazetadopovo.com.br/politica/parana/tce-pr-livrasecretario-de-richa-de-multa-por-aluguel-de-imovel-abandonado-2wvc8f5c2zt87jlfg9a98pr83> Acesso em: 26/10/17.

FGV CPDOC. Luciano Pizzatto. Disponível em < http://www.fgv.br/cpdoc/acervo/dicionarios/verbetebiografico/luciano-pizzatto> Acesso em: 12/10/17.

FILIWEB. Resultado da consulta de registro de filiação. PSB. Prudentopolis. Disponível em < http://filiaweb.tse.jus.br/filiaweb/filiacao/registro/resultadoLazy.seam?cid=71> Acesso em: 26/11/17.

FOLHA DE LONDRINA, 1998. Governo inaugura hoje o 10 ramal da Compagás. Disponível em http://www.folhadelondrina.com.br/economia/governo-inaugura-hoje-o-1-ramal-da-Compagás113550.html>. Acesso em: 04/11/2017.

GARCIA, Euclides Lucas. Copel planeja construir gasodutos e três termelétricas no Paraná. 2017. Disponível em < http://www.gazetadopovo.com.br/politica/parana/copel-planeja-construir-gasodutos-etres-termeletricas-no-parana-3uo3ezc60hse85y3zdkoxajgr>. Acesso em 05/11/2017.

GASNET, 2002. Compagás assina o primeiro contrato para fornecimento de gás residencial. Disponível em < http://www.gasnet.com.br/conteudo/208>. Acesso em 05/11/2017.

GAZETA DO POVO. MP arquiva inquérito sobre a família lurk. Meio ambiente. hidrelétricas. out. 2013. Disponível em < http://www.gazetadopovo.com.br/vida-e-cidadania/meio-ambiente/mp-arquivainquerito-sobre-a-familia-iurk-3n3uu6imvd4zf9xxxxcqkrozy> Acesso em: 25/10/17.

GASNET, 2006. GNV chega a São José dos Pinhais. Disponível em: http://www.gasnet.com.br/conteudo/1508> Acesso em 05/11/2017.

ICS- INSTITUTO CURITIBA DE SAÚDE . Diretoria. out. 2017. Disponível em < http://www.ics.curitiba.org.br/?page id=132 > Acesso em: 12/10/17.

INSTITUTO de Pesos e Medidas do Paraná tem novo presidente. Agência de notícias estado do Paraná. Governo. jan. 2011. Disponível em http://www.historico.aen.pr.gov.br/modules/noticias/article.php?storyid=61543> Acesso em: 12/10/17.

JASPER, Fernando. Crise elétrica engorda o caixa da Compagás. 2015. Disponível em http://www.gazetadopovo.com.br/economia/crise-eletrica-engorda-o-caixa-da-Compagásaknkq0x2jshvxx7k2i5uii811>. Acesso em 05/11/2017.

JHONATAN,2011. Compagás - Compagás fecha 2010 em alta e projeta investimentos para 2011. Disponível em < http://www.folhadecampolargo.com.br/noticias/geral/Compagás-7542> Acesso em 04/11/2017.

JUNIOR, José Lázaro. BNDES e governo do Paraná cogitam privatizar empresas públicas. 2017. DISPONÍVEL EM: < http://www.gazetadopovo.com.br/politica/parana/bndes-e-governo-do-parana-cogitam-privatizarempresas-publicas-4lz4fxixxf9v1dte2flzdhiq3> Acesso em 05/11/2017.

LINKED ID. Luciano Pizzato 1. Disponível em < https://br.linkedin.com/in/luciano-pizzatto-1-259a1127> Acesso em: 12/10/17.

MONTEIRO, L. M. Prosopografia de grupos sociais, políticos situados historicamente: método ou técnica de pesquisa?. Pensamento Plural. Rio Grande do Sul, n. 14, 11-21, jan./jun. 2014. Disponível em: <https://periodicos.ufpel.edu.br/ojs2/index.php/pensamentoplural/article/view/3798/3410 >. Acesso em: 25/10/2017. 
PAGOTO, Lais. Morre arquiteto Lubomir Ficinski, um dos idealizadores de Curitiba. Metro. jun. 2017. Disponível em < https://www.metrojornal.com.br/foco/2017/06/30/morre-arquiteto-lubomir-ficinski-umdos-idealizadores-de-curitiba.html > Acesso em: 27/10/17.

OLIVEIRA, Ricardo da Costa. Famílias, poder e riqueza: redes políticas no Paraná em 2007. Sociologias. Rio Grande do Sul, n. 18, 150-169, jun./dez. 2007. Disponível em < http://www.scielo.br/pdf/soc/n18/n18a08.pdf>. Acesso em: 26/10/2017.

OLIVEIRA, Ricardo Costa de. Na teia do Nepotismo : Sociologia política das relações de parentesco e poder político no Paraná e no Brasil. Curitiba: Insight, 2012.

REDAÇÃO. Multados dois ex-diretores da Sanepar por compras sem licitação em 2014. RedeSul de Noticias. mar. 2017. Disponível em

http://www.redesuldenoticias.com.br/noticias/29_03_2017_multados_dois_ex-

diretores_da_sanepar_por_compras_sem_licitacao_em_2014.htm> Acesso em: 25/10/17.

RELAÇÃO PESSOAL EM 2012. Compagás. Portal Da Transparência. Disponível em http://www.Compagás.com.br/images/pdf/transparencia/2012/201209_pessoal.pdf> Acesso em: $12 / 10 / 17$

RPC CURITIBA. Governo do Paraná anuncia mudanças no secretariado. G1.RPC Paraná. jun. 2017. Disponível em < https://g1.globo.com/pr/parana/noticia/governo-do-parana-anuncia-mudancas-nosecretariado.ghtml> Acesso em: 25/10/17.

SANEPAR. Fernando Ghignone é o novo presidente da Sanepar. Notícias. jan. 2011. Disponível em < http://site.sanepar.com.br/noticias/fernando-ghignone-e-o-novo-presidente-da-sanepar> Acesso em: 12/10/17.

SINTESE. TRF4 - Acusados de desviar dinheiro do Bolshoi são absolvidos pelo TRF4. JUSBrasil . Noticias. jan. 2017. Disponível em < https://sintese.jusbrasil.com.br/noticias/424695247/trf4-acusados-de-desviardinheiro-do-bolshoi-sao-absolvidos-pelo-trf4> Acesso em: 27/10/17.

TBG,2017. A HISTÓRIA. Disponível em < http://www.tbg.com.br/pt_br/a-tbg/historia.htm>. Acesso em 05/11/2017.

TCE-PR. Sanepar fez contrato irregular para o envase de água em copos. Tribuna. Paraná. jun. 2015. Disponível em < http://www.tribunapr.com.br/noticias/parana/sanepar-fez-contrato-irregular-para-oenvase-de-agua-em-copos/> Acesso em: 25/10/17.

TUPAN Fernando. Temer cancelará nomeações de ex-dirigentes do PPS e PSD na Itaipu. Bem Paraná. Blog do Tupan. mar. 2017. Disponível em < http://www.bemparana.com.br/tupan/temer-cancelara-nomeacoesde-ex-dirigentes-do-pps-e-psd-na-itaipu/> Acesso em: 27/10/17.

VALOR,2017. RELATÓRIO ANUAL DA ADMINISTRAÇÃO - EXERCíCIO 2016. Disponível em < http://www.valor.com.br/sites/default/files/upload_element/20.03.2017_Compagás.pdf>. Acesso em 05/11/2017. 